\title{
Solitary Large Intraoral Neurilemmoma of the Maxillary Vestibule: A Rare Case with Brief Literature Review
}

\author{
Amar Sholapurkar ${ }^{1}$, Maxim Philip Milosevic ${ }^{2}$, Varun R Mallela ${ }^{3}$, Keerthilatha M Pai ${ }^{4}$
}

\begin{abstract}
Aim: This current report aimed at presenting a rare case of a large solitary intraoral neurilemmoma of the buccal vestibule followed by a brief review of literature of neurilemmoma published between 1997 and 2017.

Background: The diagnosis of slow-growing intraoral lesions requires a thorough patient history and clinical examination. Despite the best efforts of even the most experienced oral medicine expert, a definitive diagnosis may sometimes only be reached through excisional biopsy and histopathological evaluation.

Case description: To the best of our knowledge, there have been only two cases of neurilemmoma of the buccal vestibule reported in the literature till date and, looking at the size of the lesion, our case is the largest among the ones reported.

Conclusion: In the present case, a rare presentation of solitary buccal vestibular neurilemmoma establishes the need for the consideration of a wide range of pathologies in the differential diagnosis.

Clinical significance: Clinicians should include neurilemmoma in their differential diagnosis for asymptomatic, slow-growing intraoral growths and ensure complete excision to prevent tumor recurrence. The reader should be able to recognize the clinical features of neurilemmoma and describe the histopathological features and management of the condition.

Keywords: Antoni types A and B tissues, Buccal vestibule, Neurilemmoma, Schwannoma.

The Journal of Contemporary Dental Practice (2019): 10.5005/jp-journals-10024-2609
\end{abstract}

\section{BACKGROUND}

Neurilemmoma, also known as schwannoma, neurinoma, or perineural fibroblastoma, is a benign, encapsulated neoplasm of the nerve sheath Schwann cells. ${ }^{1}$ They were first described by Verocay in 1908 and can arise from any cranial, peripheral, or autonomic nerve that contains Schwann cells. ${ }^{2,3}$ They are one of the most common neural tumors and up to one-half of cases occur in the head and the neck. ${ }^{4}$ The origin of Schwann cells occurs from the proliferation of Schwann cells in the perineurium eventually leading to tumor growth, which may cause displacement of the surrounding soft and nervous tissue. ${ }^{2}$ Their appearance intraorally is uncommon, accounting for $1 \%$ of tumors in the head and the neck region. ${ }^{5}$ In the oral cavity, the tongue is the most frequently affected, followed by the roof of the mouth, the floor of the mouth, the buccal mucosa, the gingiva, the lips, and the vestibular mucosa. ${ }^{4,5}$ While neurilemmoma can occur at any age, but the peak incidence is between the second and third decades of life. ${ }^{6}$ There is no racial or sex predilection and there are limited prevalence data.,8

Tumors are generally asymptomatic and less than $5 \mathrm{~cm}$ in size. ${ }^{6}$ Pain and discomfort may occur depending on the site and the size of the tumor. ${ }^{8}$ In their case series, over a 20 year period, Butler, Patel, and McHugh found central intraoral neurilemmoma to be more frequently associated with symptoms, when compared to their soft-tissue counterpart. ${ }^{9}$ Radiological examinations such as a cone beam-computed tomography (CBCT) scan and magnetic resonance imaging (MRI) may be performed to show the extension of the tumor. A definitive diagnosis of neurilemmoma is achieved only through histopathological evaluation. ${ }^{8}$ Surgical excision of the entire tumor is the treatment of choice..$^{4-7}$ Recurrence is rare and is usually associated with incomplete excision due to anatomical constraints. ${ }^{1,9}$

\begin{abstract}
1,2Department of Clinical Dentistry and Oral Radiology, College of Medicine and Dentistry, James Cook University, Cairns, Queensland, Australia

${ }^{3}$ Gentle Dental Fresno, Fresno, California

${ }^{4}$ Manipal College of Dental Sciences, Manipal University, Karnataka, India Corresponding Author: Amar Sholapurkar, Department of Clinical Dentistry and Oral Radiology, College of Medicine and Dentistry, James Cook University, Cairns, Queensland, Australia, Phone: +61 455254361,e-mail: amar.sholapurkar@jcu.edu.au

How to cite this article: Sholapurkar A, Milosevic MP, et al. Solitary Large Intraoral Neurilemmoma of the Maxillary Vestibule: A Rare Case with Brief Literature Review. J Contemp Dent Pract 2019;20(7):847-850. Source of support: Nil

Conflict of interest: None

The objective of this study is to report a rare and large case of neurilemmoma of the right maxillary vestibule, whose diagnosis was established upon clinical and histological findings and also a brief literature review is presented. To the best of our knowledge, there have been only two cases of neurilemmoma of the buccal vestibule reported in the literature till date..$^{5,10}$
\end{abstract}

\section{Case Description}

A 26-year-old male patient was referred to our department by a general dentist to evaluate a swelling in the right maxillary quadrant. The patient complained of a swelling in this region which had been present for 2 years. The swelling was small initially and gradually grew to the present dimensions. There was no accompanying pain, purulent exudate, paresthesia, or numbness. The patient did not report any similar swellings elsewhere in the body. He had not consulted a specialist and no treatment had been

(0) The Author(s). 2019 Open Access This article is distributed under the terms of the Creative Commons Attribution 4.0 International License (https://creativecommons. org/licenses/by-nc/4.0/), which permits unrestricted use, distribution, and non-commercial reproduction in any medium, provided you give appropriate credit to the original author(s) and the source, provide a link to the Creative Commons license, and indicate if changes were made. The Creative Commons Public Domain Dedication waiver (http://creativecommons.org/publicdomain/zero/1.0/) applies to the data made available in this article, unless otherwise stated. 
instituted as the swelling was asymptomatic. The family history was unremarkable and the medical history was noncontributory.

Extraoral examination revealed slight distension of the upper lip on the right side and a mild facial deformity in the same region. There was no evidence of any lymph node enlargement. Intraoral examination revealed a large swelling of approximately $4 \times 3 \mathrm{~cm}$ in size that extended mesiodistally from the UR3 region to the UR6 region and obliterating the mesiobuccal fold superio-inferiorly (Fig. 1). The swelling was sessile and did not differ in color from the adjacent mucosa. The soft tissue in other areas of the mouth did not display any abnormalities. There was no tenderness on palpation. An extensive periodontal evaluation revealed no significant abnormalities. The teeth were stable and did not show any malalignment. Cold sensibility testing of UR3-UR6 inclusive revealed that all teeth were vital. Periapical radiography failed to reveal any abnormalities (Fig. 2). At this stage, based on the above clinical findings, provisional diagnoses were established as some benign soft-tissue tumor or minor salivary gland tumor. The differential diagnosis of pyogenic granulomas, irritation fibromas, neurofibromas, neurilemmomas, lipomas, granular cell tumors, leiomyomas, and rhabdomyomas was considered and this was based on the type of epithelial and connective tissues associated in that area of interest.

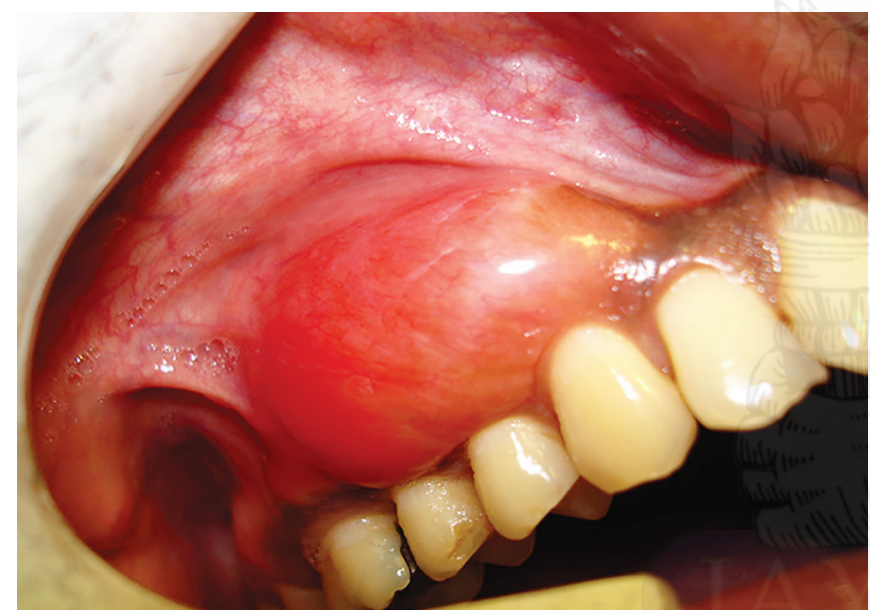

Fig. 1:Well-defined localized swelling in the maxillary vestibular region obliterating the buccal-mucobuccal fold

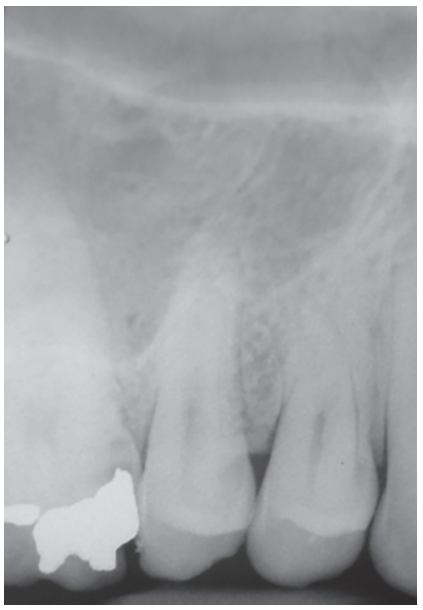

Fig. 2: Periapical radiograph of the region of interest showing no evidence of any abnormality

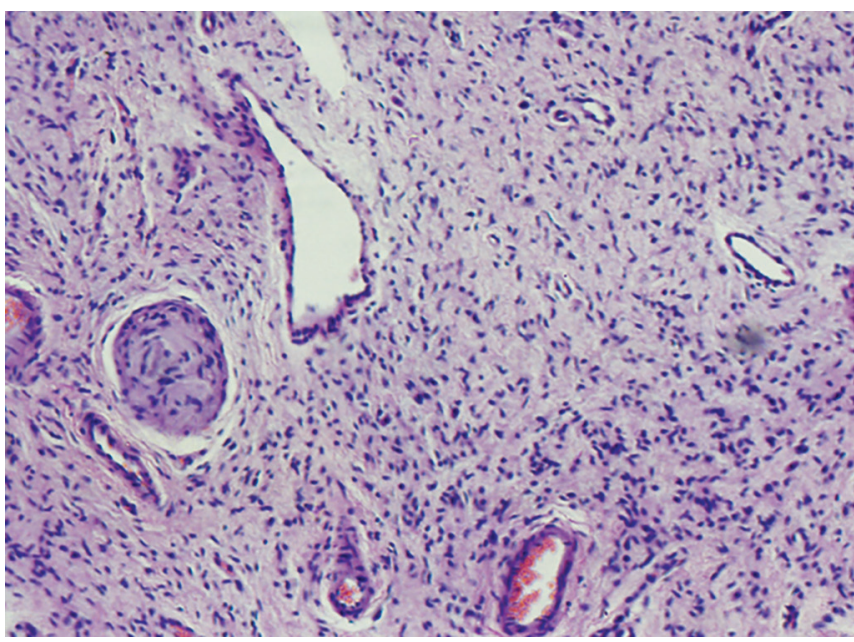

Fig. 3: Microscopic examination of the mass. Section stained with hematoxylin and eosin $(200 \times)$ showing a diffuse lesion composed of spindle cells with thin-walled congested vessels and occasional entrapped nerve fibers. Both Antoni A (with well-organized, high cellularity) and Antoni B tissues (with less cellularity) were detected

Fine-needle aspiration biopsy (FNAB) was first performed, which showed fragments of tissues consisting of cells aligned to depict nuclear palisading as well as dissociated nuclei and peripheral blood elements. Incisional biopsy was under local anesthesia and tissue samples were submitted for histopathological examination. Histopathological evaluation revealed a spindle-cell tumor consisting of two types of tissue: Antoni A and Antoni B (Fig. 3-H\&E staining, $\times 200$ ). Section stained with hematoxylin and eosin $(200 \times)$ showed a diffuse lesion composed of spindle cells with thin-walled congested vessels, occasional entrapped nerve fibers, and no evidence of rosettes. Both Antoni A (with well-organized, high cellularity) and Antoni B tissues (with less cellularity) were detected.

The presence of these tissues was consistent with neurilemmoma. In the light of the final diagnosis, a thorough physical examination was made to rule out any multiple tumors of neural origin; however, the results were negative.

Based on the patient history, clinical examination, and histopathologic investigation, the definitive diagnosis was determined to be solitary neurilemmoma of the buccal vestibule. The patient was admitted and the lesion was surgically excised under local anesthesia followed by suturing. The postoperative period was, however, uneventful. Gross examination of the specimen revealed that it was partially encapsulated and firm in consistency (Fig. 4). The patient was recalled after 1 week for suture removal which caused little or no discomfort for the patient. The patient was further followed up after a month that posed no discomfort.

\section{Discussion}

An Ovid Medline search for the MeSH terms "neurilemmoma" and "mouth" returned 123 case reports published between 1997 and 2018. Neurilemmoma is a benign, encapsulated nerve sheath tumor which can occur in a solitary form or as a part of genetic diseases including neurofibromatosis (NF) type I, NF type II, and schwannamotosis. ${ }^{4}$ Lesions may be further classified into central or peripheral type. ${ }^{5}$ While the precise etiology is unknown, mutation of the NF2 Schwann cell regulator gene is implicated. ${ }^{4}$ It is 


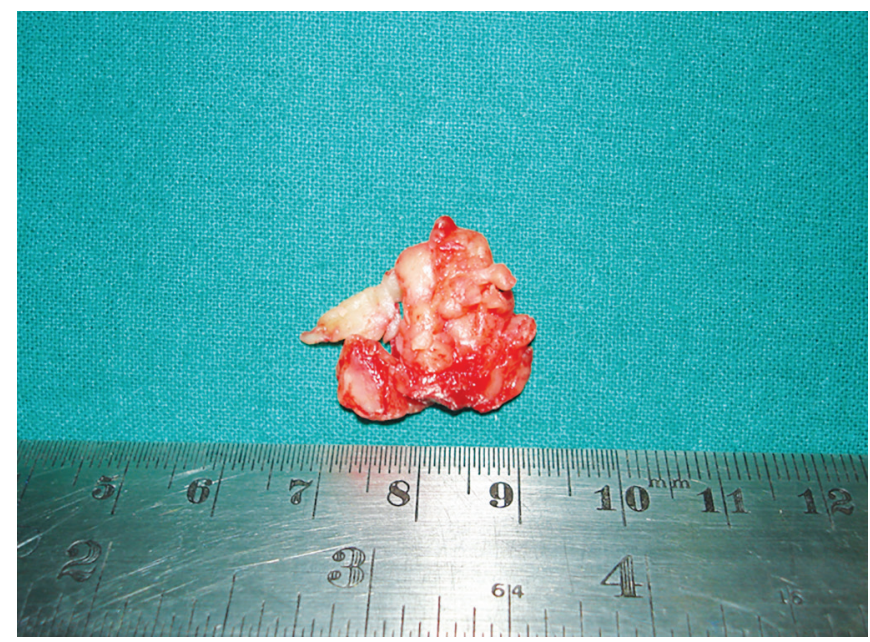

Fig. 4: Photograph of the excised specimen

hypothesized that lesions occur due to the proliferation of Schwann cells, leading to compression and displacement of the associated nerve. ${ }^{6}$ In most cases of the head and neck neurilemmoma, the facial nerve is affected in the form of acoustic neuromas. ${ }^{2}$ Of the $1 \%$ of lesions occurring in the oral cavity, the tongue is the most common site followed by the roof of the mouth, the floor of the mouth, the buccal mucosa, the gingiva, the lips, and the vestibular mucosa. ${ }^{4}$ Our case is, however, involving the least involved sites and looking at the size of the lesion, it is the largest among the ones reported till date. ${ }^{2}$

Our patient was referred by his general dentist and had no complaint other than swelling. As in our case, the typical appearance is a well-circumscribed growth which mimics other benign soft-tissue lesions. ${ }^{11}$ Neurilemmoma has no pathognomonic morphological feature, however. The rarity of the lesion intraorally, absence of genetic condition combined with the atypical location in our case rendered a provisional diagnosis of neurilemmoma difficult. Radiographically, central lesions are often detected incidentally as they may cause bone resorption. Of the available imaging modalities, high-resolution CBCT provides the greatest level of information regarding lesion size, extent, and involvement of the bone. ${ }^{7,8}$ Bony lesions typically appear as a well-defined unilocular radiolucency with a thin cortical margin. ${ }^{5}$ A heterogenous radiographic appearance may be suggestive malignant changes in the tumor. ${ }^{6}$ Alim et al. suggest that MRI is suitable if there is suspicion of infraorbital or intracranial extension. ${ }^{7}$ Since intraoral radiography in our case revealed no signs of bony involvement (Fig. 2) and also because of financial constraints, no further radiographic investigation was indicated.

Definitive diagnosis is usually confirmed only by histopathological examination. ${ }^{4}$ While all intraoral neurilemmoma is encapsulated, some extraoral tumors may lack this feature. ${ }^{9}$ Beneath the capsule, neurilemmoma display two characteristic histopathological patterns: Antoni A and B. Antoni A comprises palisading spindle cells arranged around acellular areas known as Verocay bodies. ${ }^{2}$ Antoni B comprises hypocellular myxoid areas of randomly arranged spindle cells. ${ }^{2}$ Both Antoni A and Antoni B tissues (Fig. 3) were detected and this confirmed the diagnosis of neurilemmoma in our case. As seen in Figure 3, blood vessels with thickened hyaline walls may also be present. ${ }^{2}$ Immunohistochemical features can be useful in determining the neural differentiation.
Because of their Schwann cell's nature, neurilemmoma also displays strong immunohistochemical positivity to S-100 and Leu 7 antigen. ${ }^{8}$ Long-standing neurilemmoma may mimic malignancy histologically due to the presence of nuclear pleomorphism and hyperchromatism; these lesions are named ancient schwannomas. ${ }^{8}$ The Antoni B pattern is also detected histologically in neurofibroma. However, the two can be distinguished as neurofibroma stains for Factor XIIla, while neurilemmoma does not. ${ }^{8}$

Recurrence of neurilemmoma is rare and is usually associated with incomplete excision due to anatomical constraints. $4,9,12,13$ Hashiba et al. reported a case of recurrent neurilemmoma of the upper lip which recurred 9 months after the initial excision and 7 months after the second excision. ${ }^{14}$ It was completely resolved following a third surgery. Malignant transformation is very rare and usually occurs in the form of malignant peripheral nerve sheath tumor. ${ }^{4}$ Nevertheless, Guglielmotti et al. described a case of malignant neurilemmoma in the gingivae of an 18-year-old male. ${ }^{15}$ Kurup et al. assert the importance of complete resolution of the tumor due to the slight but real possibility of malignancy. ${ }^{8}$

\section{Conclusion}

In the present case, a rare presentation of solitary buccal vestibular neurilemmoma establishes the need for the consideration of a wide range of pathologies in the differential diagnosis.

\section{Clinical Significance}

Clinicians should include neurilemmoma in their differential diagnosis for asymptomatic, slow-growing intraoral growths and ensure complete excision to prevent tumor recurrence. The reader should be able to recognize the clinical features of neurilemmoma and describe the histopathological features and management of the condition.

\section{References}

1. Martins MD, Anunciato de Jesus L, et al. Intra-oral schwannoma: case report and literature review. Indian J Dent Res 2009 JanMar;20(1):121-125.

2. Handschel J, Heikaus S, et al. Intraoral schwannoma: review of the literature and presentation of a rare case. Cranio 2012;30(2):150-153. DOI: 10.1179/crn.2012.022.

3. Parhar S, Singh HP, et al. Intra-oral schwannoma-a case report. JClin Diagn Res 2014 Mar;8(3):264-265. DOI: 10.7860/JCDR/2014/7466. 4181.

4. Kavči J. Schwannoma of the tongue. BMJ Case Rep 2016;2016, DOI: 10.1136/bcr-2016-215799.

5. Kandasamy S, Nathan RS, et al. Neurilemmoma of maxillary alveolus: a rare case report and review of literature. J Pharm Bioallied Sci 2017;9(Suppl 1):S285-S288. DOI: 10.4103/jpbs.JPBS_114_17.

6. Shim S-K, Myoung $\mathrm{H}$. Neurilemmoma in the floor of the mouth: a case report. J Korean Assoc Oral Maxillofac Surg 2016;42(1):60-64. DOI: 10.5125/jkaoms.2016.42.1.60.

7. Alim BM, Jomah M, et al. Maxillary sinus schwannoma. BMJ Case Rep 2018 May 30;2018, DOI: 10.1136/bcr-2017-223946.

8. Kurup S, Thankappan K, et al. Intraoral schwannoma-a report of two cases. BMJ Case Rep 2012;2012. DOI: 10.1136/bcr.12.2011. 5389.

9. Butler RT, Patel RM, et al. Head and neck schwannomas: 20-year experience of a single institution excluding cutaneous and acoustic sites. Head Neck Pathol 2016;10(3):286-291. DOI: 10.1007/s12105016-0680-2. 
10. Subhashraj $K$, Balanand $S$, et al. Ancient schwannoma arising from mental nerve. A case report and review. Med Oral Patol Oral Cir Bucal 2009 Jan 1;14(1):E12-E14.

11. Purwar $P$, Dixit J, et al. Conflation of gingival overgrowth and schwannoma. BMJ Case Rep 2014;2014, DOI: 10.1136/bcr-2014-205879.

12. Rathore AS, Srivastava D, et al. Neurilemmoma of retromolar region in the oral cavity. Case Rep Dent 2015;2015:320830. DOI: $10.1155 / 2015 / 320830$.
13. Shim SK, Myoung H. Neurilemmoma in the floor of the mouth: a case report. J Korean Assoc Oral Maxillofac Surg 2016 Feb;42(1):60-64. DOI: 10.5125/jkaoms.2016.42.1.60.

14. Hashiba Y, Nozaki S, et al. Recurrent multinodular neurilemmoma of the female upper lip. Int J Oral Maxillofac Surg 2007;36(2):171-173. DOI: 10.1016/j.ijom.2006.07.001.

15. Guglielmotti MB, Peña C, et al. Malignant schwannoma of the gingiva. Int J Oral Maxillofac Surg 1987;16(4):492-495. 